\title{
Temperature and Precipitation Trends Using CMIP6 Model Data Using the Different Senarios in Jimma Zone, ONRS of Ethiopia
}

\author{
Gemechu Fufa $(\mathrm{PhD})^{1}$ Solomo Addisu $(\mathrm{PhD} \text {, Associate professor })^{2}$ \\ Alemayehu Regassa $\left(\mathrm{PhD}\right.$, Associate professor) ${ }^{3}$ \\ 1.Jimma University College of Agriculture and Veterinary Medicine Department of Natural Resource \\ Management \\ 2.Bahir Dar University, College of Agriculture and Environmental Sciences \\ 3.Jimma University College of Agriculture and Veterinary Medicine Department of Natural Resource \\ Management
}

\begin{abstract}
The Coupled Model Intercomparison Project Phase 6 (CMIP6) dataset is used to examine projected trend in temperature and precipitation over Jimma zone. The changes are computed under three Shared Socioeconomic Pathways (SSPs; SSP1-2.6, SSP2-4.5, SSP6 and SSP5-8.5) from 1980-2020. This study was undertaken to analyze rainfall and Temperature trend in Jimma zone, ONRS of Ethiopia. The study employed Mann-Kendall's test to detect change in rainfall trends. Results for rainfall trend analysis for Jimma zone indicated decreasing trends, Overall, the observed trends were not statistically significant at $1 \%$ and $5 \%$. Temperature is projected to increase over the entire domain under all three SSPs, by as much as $6{ }^{\circ} \mathrm{C}$ under SSP5-8.5, and with more pronounced increased. The mean temperature in the study area ranges from $20^{\circ} \mathrm{C}$ to $25^{\circ} \mathrm{C}$ with annual average temperature of 22 ' $\mathrm{C}$. The rate of change of temperature was found to be $0.0181,0.3536,0.2041$ and $0.026{ }^{\circ} \mathrm{C}$ per decade for mean, minimum and maximum respectively during the period of 1980-2020. The results of MK test for monthly precipitation data revealed a statistically significant decreasing trend (at 10\% level of significance). attributed to an increase in the minimum temperature. It is, therefore, imperative to adjust the agriculture activity with the variability situation and design planned climate change adaptation strategies so as to enhance the adaptive capacity and resilience of rainfed dependent smallholder farmers
\end{abstract}

Keywords: Climate change, CMIP6, Temperature, Precipitation

DOI: $10.7176 / \mathrm{JRDM} / 79-02$

Publication date:October $31^{\text {st }} 2021$

\section{Introduction}

\subsection{Background}

Climate change is one of the greatest challenges faced by humankind as it poses an existential threat to many aspects of the current social-ecological landscape of natural and human systems (Almazroui et al., 2021). Since 1950 , a decrease in the amount of snow, a heating ocean, and rising sea levels have been noticed as results of climate system warming. The climate system has been influenced by human-induced forces activities for centuries. However, the impact of human activities started to extend to a global scale since the start of the industrial revolution (Birara \& Mishra, 2020) Scientists have reached a consensus that the global annual average temperature is likely to be $2{ }^{\circ} \mathrm{C}$ above pre-industrial levels by 2050 , and a $2{ }^{\circ} \mathrm{C}$ warmer world will experience more intense rainfall and more frequent and more intense droughts, floods, heat waves, and other extreme weather events (Feyissa et al., 2018). Africa, the second most populous continent in the world, is one of the region's most vulnerable to climate change due to its high exposure and low adaptive capacity (Almazroui et al., 2020a).

Africa, the second-largest Continent on earth and with the fastest population growth, along with an economy reliant on rain-fed agriculture, is among the places most sensitive to climate variability and change. Changes in variability, extremes, and mean of temperature and rainfall make themselves felt in day-to-day life through heat stress, floods, droughts, and other impacts on both human society and natural ecosystems in Africa (Almazroui et al., 2020b).

The IPCC (2013) report indicated that Ethiopia will be more vulnerable to climate change due to its less flexible economic structure and its dependence on rain-fed agriculture. Changes in seasonal patterns and precipitation distribution, timing, and pattern, as well as temperature, are already being witnessed in most parts of the country. In many parts of the country, precipitation is becoming more unpredictable every season and every year. Temperature and precipitation variables are the most important measures that indicate changes in climate. Climate variability and change are among the greatest developmental challenges of the 21 st century (Miheretu, 2020).

Climate change will have far-reaching consequences for agriculture that will disproportionately affect poor and marginalized groups who depend on agriculture for their livelihoods and have a lower capacity to adapt. The agriculture system in Ethiopia is dominated by rain fed agriculture, where the performance of the sector is highly dependent on the timely onset, duration, amount and distribution of rainfall (Gebrechorkos et al., 2019). 
Rainfall is the most important element that limits the productivity of crops. Proper analysis of rainfall trend and understanding of its relationship with land productivity may help in planning purposes. The seasonal characteristic of rainfall is an important climatic element that affects the productivity and production potential of crops in the subsistence agricultural systems. With the current climate change threat, slight variabilities in the availability of rainfall can lead to a significant impact on crop yields (Molla \& Fitsume, 2017).

Ethiopia is among the largest countries of Africa and it is characterized by a wide variety of landscapes, with marked contrasts in relief and altitudes ranging from about $155 \mathrm{~m}$ below sea level of Assale Lake, in the Danakil depression, to about 4,533 $\mathrm{m}$ a.s.l. at Ras Dejen. For these reasons and given its geographic position close to the equator and the Indian Ocean, the country is subjected to large spatial variations in temperature and precipitation (Fazzini et al., 2015).

The climate of Ethiopia is therefore mainly controlled by the seasonal migration of the Intertropical Convergence Zone (ITCZ) and associated atmospheric circulations as well as by the complex topography of the country. Landscapes with contrasting characteristics in terms of physiography and elevation, such as the highlands and the lowlands, experience a variety of climates from desert climate to that typical of equatorial mountains.

The Bega season occurs from October to January, Belg form February to May and Kiremt from June to September. Hence, Bega rainfall amount of a given year is the sum of October-December rainfall amount of the given year plus rainfall amount of January of the coming year. Similarly the seasonal rainfall amount of Kiremt and Belg seasons defined as the sum of rainfall amount of each month rainfall in the season respectively (B. Barana, 2017).

The Coupled Model Intercomparison Project (CMIP) has been coordinating simulations conducted by international modeling groups since the $1990 \mathrm{~s}$, with the aim of improving the performance of climate models and enhancing the scientific understanding of the climate system. This project has become a major tool for climate science, and remarkable progress has been achieved for global climate models (GCMs). Temperature and precipitation are essential indicators for climate change. In the past few years, many research efforts have been devoted to model evaluations and projections of temperature and precipitation over China within the CMIP phase 5 (CMIP5) framework (Yang et al., 2021).

\subsection{Statement of the Problem}

Precipitation and Temperature are one of the most complex climatic variables(Klutse et al., 2021). In particular, rainfall is the most significant meteorological parameter in Ethiopia, as approximately $85 \%$ of the Ethiopian labor force is employed in rain-fed agriculture which highly depends on low or high amounts of rainfall availability vital for crop production (Alhamshry et al., 2020).

The geography of Ethiopia presents a difficult test for climate models. The central part of Ethiopia is dominated by the East African Highlands (the Semain and Bale mountains) which split the country climatically. Knowing the variations in the general rainfall pattern is vital to understand the climate change variations and its consequence on ecosystem (Girma et al., 2016). Precipitation trend analysis on different spatial and temporal scales, has been of great concern during the past century because of the attention given to global climate change by the scientific community. Assessing rainfall and Temperature trends are paramount to understanding the variations in space and time. In Ethiopia, several studies have been carried out on rainfall and temperature trend analysis based on historical data of some selected weather stations (Baley, 2014). However, mean annual temperature in Ethiopia has increased by $1.3^{\circ} \mathrm{C}$ between 1960 and 2006, at an average rate of $0.28^{\circ} \mathrm{C}$ per decade increased (McSweeney et al., 2008). On other hand, Wing et al. (2008) report shows a significant decline in main season (June to September) rainfall was recorded in the southwestern and central parts of Ethiopia. Similarly, Baley (2014) findings revealed declined rainfall in central rift valley of Ethiopia. It is very difficult to detect long-term rainfall trends in Ethiopia, due to the high inter-annual and inter-decadal rainfall variability. Assessing trends in rainfall and Temperature based on past records helps with better understanding of problem associated with drought, floods and various water uses (Jain et al., 2012).

Therefore, this study addresses these gaps by assessing the future climate responses at a subregional scale over these regions through the analysis of a large suite of CMIP6 GCMs under various Shared Socioeconomic Pathways (SSP) scenarios.

\subsection{Objective}

1.3.1. General Objective

To evaluate Temperature and Precipitation trends using CMIP6 model data using the different senarios in Jimma Zone, ONRS and Ethiopia

1.3.2. Specific Objectives

2. To analayse Temperature trends using CMIP6 model data using the different senarios in Jimma Zone, ONRS and Ethiopia

3. To evaluate precipitation trends using CMIP6 model data using the different senarios in Jimma Zone, ONRS 
and Ethiopia

\section{Methodology}

\subsection{Description of the study area}

Jimma is one of the zones of the Ethiopian Region of Oromia. Jimma is named for the former Kingdom of Jimma, which was absorbed into the former province of Kaffa in 1932. Jimma is bordered on the south by the Southern Nations, Nationalities and Peoples Region, the northwest by Illubabor Zone, on the north by East Welega Zone and on the northeast by West Shewa Zone; part of the boundary with South west East Shewa Zone is defined by the Gibe River. The highest point in this zone is Mount Maigudo (2,386 m). Jimma zone situated approximately between 7.4-7.7 $\mathrm{N}$ and 36.5-36.8.

\section{Climate of Jimma}

Jimma has a relatively cool tropical monsoon climate (Köppen climate classification: Am) under the Köppen climate classification. It features a long annual wet season from March to October. Temperatures at Jimma are in a comfortable range, with the daily mean staying between $20^{\circ} \mathrm{C}$ and $25^{\circ} \mathrm{C}$ year-round.

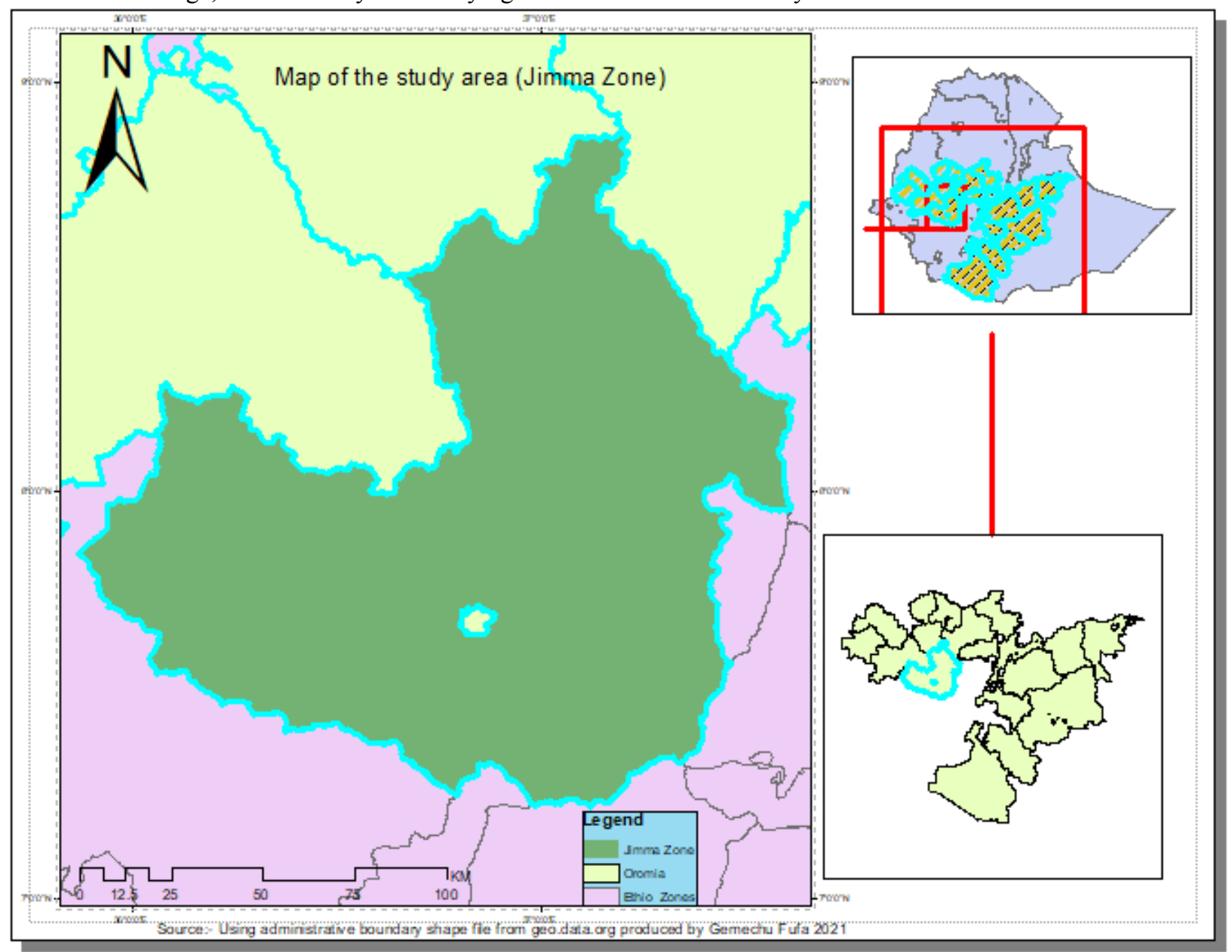

Figure 1: Map of the study area

\subsection{Research design}

\subsubsection{Data type and source}

Rainfall and temperature data for trend analysis have been obtained from different sources. monthly precipitation from Climate Research Unit (CRU TS 3.23) with 0.5 by 0.5 resolution from 2000 to 2040 was obtained and used for trend analysis (downloaded from Climate explorer: KNMI Climate change atlas. https:// climexp.knmi.nl/plot_atlas_form.py).

\subsection{Modeled data.}

I obtained monthly surface air temperature output from GCMs in the CMIP6 archive. One sets of experiments were used focusing on the global land area and the continental scale: one historical simulations for the period 1901-2014 were processed for the performance analysis; Four scenarios (SSP1- 2.6, SSP2-4.5, SSP3-7.0 and SSP5-8.5) were used for projections of trends from 1980 to 2020, which provide a full range of forcing targets 
similar in both magnitude and distribution to the SSPs as used in CMIP6. All the models were bilinearly interpolated onto a common grid of $1 \circ \times 1 \circ$ for comparison between simulations and observations (Gidden et al., 2019).

\subsection{Data analysis techniques}

A number of techniques have been developed for the analysis of rainfall and temperature trend analysis. Trend detection and analysis are performed through parametric and non-parametric tests only for consistent data. As a result, MannKendall (MK) test is widely used to detect trends of meteorological variables (Gebremedhin et al., 2016). MK test is a nonparametric test, which tests for a trend in a time series without specifying whether the trend is linear or non-linear. MK was used to detect the trend of rainfall and temperature with Sen's slope estimator (test Pettitt's test was used to test the degree of homogeneity of the data); Data analysis was undertaken using XLSTAT software and excel spreadsheet.

MK trend test is a non-parametric test commonly employed to detect monotonic trends in series of climate data. MK test has been used to detect the presence of monotonic (increasing or decreasing) trends in the study area and whether the trend is statistically significant or not. Since there are chances of outliers to be present in the dataset, the non-parametric MK test is useful because its statistic is based on the (bor -) signs, rather than the values of the random variable, and therefore, the trends determined are less affected by the outliers (Birsan et al., 2005).

Trend analysis has been carried out on monthly and annual bases. Since the study area gets its kiremt rainfall from June to September, monthly trends for these four months have been analyzed separately. This enables us to see the trend especially for the onset and cessation months. Homogeneity test was undertaken using Pettitt's test. Each data value is compared with all subsequent data values. If a data value from a later time period is higher than a data value from an earlier time period, the statistic $\mathrm{S}$ is incremented by 1 . On the other hand, if the data value from a later time period is lower than a data value sampled earlier, $\mathrm{S}$ is decremented by 1 . The net result of all such increments and decrements yields the final value of S. The MK test statistic ' $S$ ' is calculated based on Mann (1945), Kendall (1975) and Yue et al. (2002) using the formula:

$S=\sum_{i=1}^{n-1} \sum_{j=i+1}^{n} \operatorname{sgn}(x j-x i)$

The application of trend test is done to a time series Xi that is ranked from $\mathrm{i} 1 / 41,2 \ldots \mathrm{n}-1$ and $\mathrm{Xj}$, which is ranked from $\mathrm{j} 1 / 4 \mathrm{i} \mathrm{p} 1,2 \ldots \mathrm{n}$. Each of the data point $\mathrm{Xi}$ is taken as a reference point which is compared with the rest of the data point's $\mathrm{Xj}$ so that:

$\operatorname{sgn}(x j-x i)=\left\{\begin{array}{c}+1 i f(x j-x i)>0 \\ 0 i f(x j-x i)=0 \\ -1 i f(x j-x i)<0\end{array}\right.$.

Where $\mathrm{Xi}$ and $\mathrm{Xj}$ are the annual values in years $\mathrm{i}$ and $\mathrm{j}(\mathrm{j}>\mathrm{i})$ respectively. It has been documented that when the number of observations is more than 10 (n 10), the statistic ' $\mathrm{S}$ ' is approximately normally distributed with the mean and $\mathrm{E}(\mathrm{S})$ becomes 0 (Kendall, 1975). In this case, the variance statistic is given as:

$\operatorname{Var}(S)=\frac{n(n-1)(2 n+5)-\sum_{t=1}^{m} t 1(t 1-1)(2 t 1+5}{18}$

where $\mathrm{n}$ is the number of observation and ti are the ties of the sample time series. The test statistics $\mathrm{Zc}$ is as follows:

$$
Z=\left\{\begin{array}{l}
\frac{S-1}{\sigma} \text { if } S>0 \\
0 \text { if } S=0 \\
\frac{S-1}{\sigma} \text { if } S<0
\end{array}\right.
$$

Where $\mathrm{Zc}$ follows a normal distribution, a positive $\mathrm{Zc}$ and a negative $\mathrm{Zc}$ depict an upward and downwards trend for the period respectively. Sen's Slope estimation test computes both the slope (i.e. the linear rate of change) and intercept according to Sen's method. The magnitude of the trend is predicted by Theil (1950) and Sen (1968) slope estimator methods. A positive value of $\beta$ indicates an 'upward trend' (increasing values with time), while a negative value of $\beta$ indicates a 'downward trend'. Here, the slope (Ti) of all data pairs is computed as (Sen, 1968). In general, the slope Ti between any two values of a time series $\mathrm{x}$ can be estimated from:

$T=\frac{x j-x i}{j-i}$

Where $\mathrm{xj}$ and $\mathrm{xk}$ are considered as data values at time $\mathrm{j}$ and $\mathrm{k}(\mathrm{j}>\mathrm{i}$ ) correspondingly. The median of these $\mathrm{N}$ values of Ti is represented as Sen's estimator of slope which is computed as Qmed $1 / 4 \mathrm{~T}(\mathrm{~N}+1) / 2$ if $\mathrm{N}$ appears odd, and it is considered as Qmed $1 / 4[\mathrm{TN} / 2+\mathrm{T}((\mathrm{N}+2) / 2) / 2]$ if $\mathrm{N}$ appears even. A positive value of Qi indicates an upward or increasing trend and a negative value of Qi gives a downward or decreasing trend in the time series.

\section{Results and Discussions}

The monthly and annual mean of time series data of climatic parameters, particularly temperature (maximum and minimum) and precipitation was analyzed using MK test for Jimma zone. Table 2 shows MK statistics and p- 
values derived at $10 \%$ and $5 \%$ level of significances. In the MK test, parameters like Kendall's tau, S statistic, and the $\mathrm{Z}$ statistic were considered to identify the increasing or decreasing trend in the time series of climatic parameters. The test results are discussed in detail separately for each parameter.

\subsection{Precipitation Trend Analysis Result}

The MK test and Sen's slope estimator were applied to the time-series data from 1980 to 2020 for Jimma zone. The results of MK test for trend analysis are presented in Table 2. The trend analysis has been done for all months of the year. The results of MK test for monthly precipitation data revealed a statistically significant decreasing trend (at 10\% level of significance). The results are different from the findings where statistically non-significant increasing trend was recorded in all seasons (including annual time scale) (Girma et al., 2016) and Arragaw and Woldeamlak (2017) where statistically significant increasing trends in July and November in dega and woinadega agroecologies of central highlands of Ethiopia were reported. In this study, highly variable but non-significant decreasing trend of belg rain through time was obtained which coincides with Arragaw and Woldeamlak (2017) where belg rainfall showed a significant decreasing trend.

As depicted in Fig. 1, rainfall has been decreasing. Rainfall during September is essential because the crops during this time are at flowering or ripening stage and require more water for maturation. Slight perturbations such as temperature fluctuations at critical points in crop growth can have considerable effects on later productivity. Trend analysis was also conducted based on KNMI data using CMIP6 model result was obtained. As depicted in Table 1, rainfall has been decreased in the study area and the trend is statistically significant in SSP12.6 and SSP8.5. On the other hand, a decreasing but insignificant trend has been detected for SSP4.5 and SSP 6. Overall, a decreasing trend of rainfall has been detected in the Jimma zone. Furthermore, Overall rainfall in the Jimma zone has shown an insignificant decreasing trend.

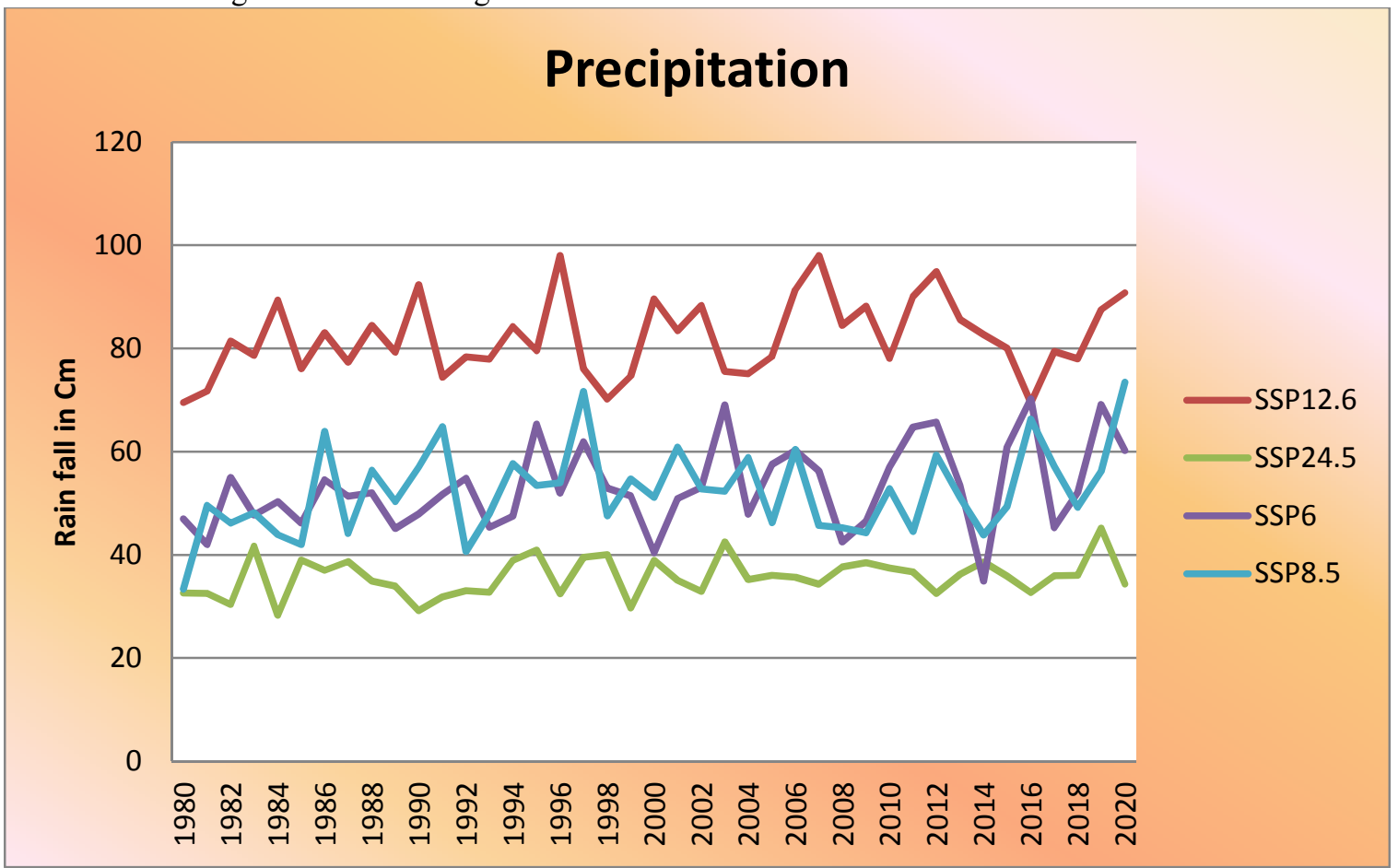

Figure 2: Rain fall trend for Jimma zone from 1980-2020

Table 1: Slope of precipitation for Jimma zone from 1980-2020

\begin{tabular}{llc}
\hline Scenario's & Slope of precipitation & \\
\hline ssp12.6 & $\mathrm{y}=0.1606 \mathrm{x}+78.729$ & $\mathrm{R}^{2}=0.0664$ \\
ssp24.5 & $\mathrm{y}=0.0784 \mathrm{x}+34.107$ & $\mathrm{R}^{2}=0.0632$ \\
ssp6 & $\mathrm{y}=0.2479 \mathrm{x}+47.97$ & $\mathrm{R}^{2}=0.1293$ \\
ssp8.5 & $\mathrm{y}=0.1981 \mathrm{x}+48.245$ & $\mathrm{R}^{2}=0.0789$ \\
\hline
\end{tabular}


Table 2: MK trend analysis of rainfall for Jimma zone from(1980-2020)

\begin{tabular}{|c|c|c|c|c|c|c|}
\hline Scenarios & Z-value & Sen's slope & $\mathbf{S}$ & $\operatorname{Var}(s)$ & P-value & Tau \\
\hline SSP2.6 & 1.6286310 & $0.1737646 *$ & 146.00000 & 7926.667 & $0.1033912 *$ & $0.1780488^{*}$ \\
\hline Ssp 4.5 & $1.246745 \mathrm{e}+00$ & $\begin{array}{l}6.778629 \mathrm{e}- \\
02\end{array}$ & $1.120000 \mathrm{e}+02$ & $7.926667 \mathrm{e}+03$ & $\begin{array}{l}2.124910 \mathrm{e}- \\
01\end{array}$ & $\begin{array}{l}1.365854 \mathrm{e}- \\
01\end{array}$ \\
\hline SSP6 & $2.482258 \mathrm{e}+00$ & $\begin{array}{l}2.798595 \mathrm{e}- \\
01\end{array}$ & $2.220000 \mathrm{e}+02$ & $7.926667 \mathrm{e}+03$ & $\begin{array}{l}1.305526 \mathrm{e}- \\
02\end{array}$ & $\begin{array}{l}2.707317 \mathrm{e}- \\
01\end{array}$ \\
\hline SSP8.5 & 1.3590645 & $0.1648943^{*}$ & 122.0000000 & 7926.667 & $0.1741261 *$ & $0.1487805^{*}$ \\
\hline
\end{tabular}

Note:-* significant at $10 \%$

\subsection{Temperature Trend Analysis Result}

An increase in temperature is among the manifestations of global climate change. The mean temperature in the study area ranges from 20 ' $\mathrm{C}$ (minimum) to $25^{\prime} \mathrm{C}$ (maximum) with annual average temperature of $22^{\prime} \mathrm{C}$. The long range of mean annual temperature showed inter-annual variability while the trend after 1980 has been higher than the long term average which is evidence for the presence of warming trend since the last decade of 20th century. As demonstrated in Table 4, MK trend test result revealed that mean and minimum average temperatures have been increasing through time significantly at $95 \%$ confidence level. The trend for monthly maximum temperature showed a non-significant increasing trend (except for the months of April and November) while a significant increasing trend for minimum monthly temperature was obtained for all months. The overall increase in annual temperature observed in the study area is attributed to an increase in the minimum temperature (the increment of the minimum temperature is more pronounced than the maximum). The result is in agreement with the findings of Stafford et al. (2000), Conway et al. (2004), Tabari and Talaee (2011), Roy and Das (2013) and Daniel et al. (2014) where the increasing trends in the Tmin series were higher than those in the Tmax series.

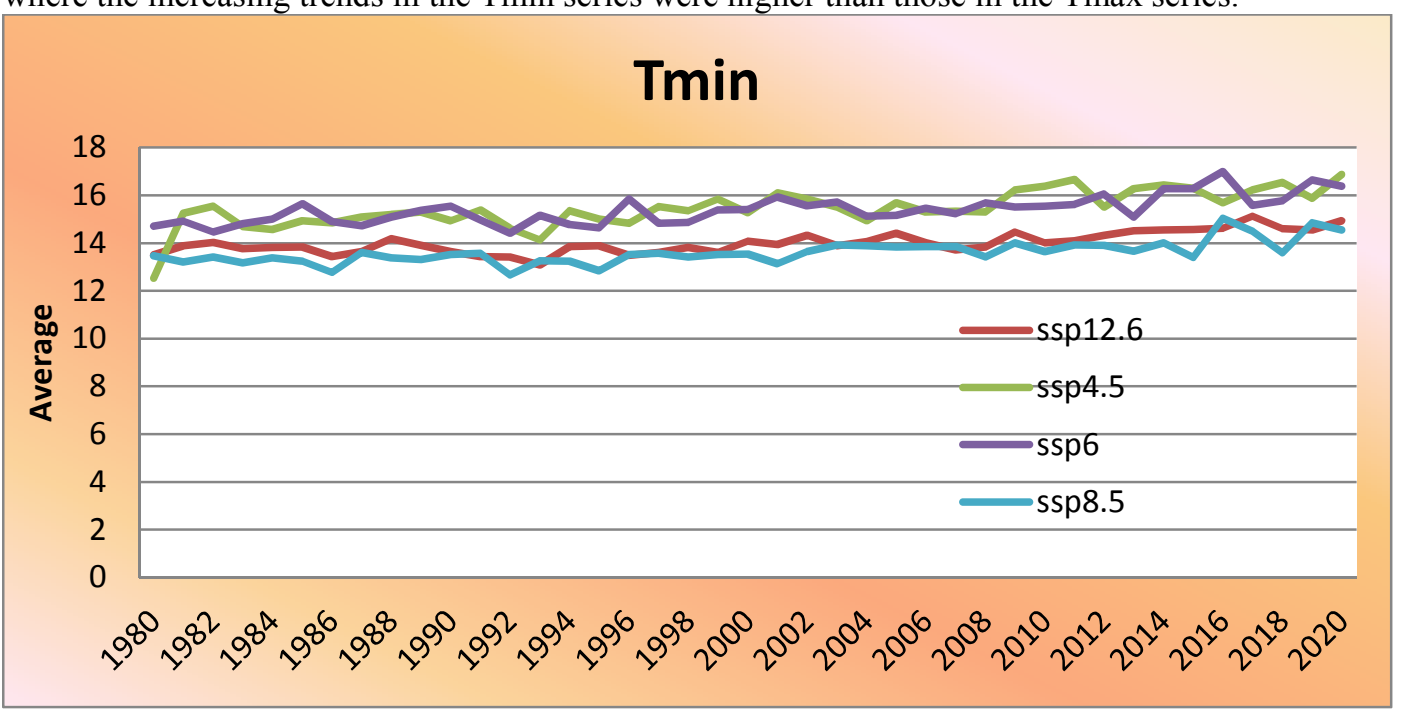

Figure 3: Trend analysis of minum temperature for Jimma zone from 1980-2020

Table 3: Slope of minimum temperature for jimma zone from 1980-2020

\begin{tabular}{lll}
\hline Trend & slope & \\
\hline ssp12.6 & $\mathrm{y}=0.0275 \mathrm{x}+13.433$ & $\mathrm{R}^{2}=0.5458$ \\
ssp4.5 & $\mathrm{y}=0.0483 \mathrm{x}+14.428$ & $\mathrm{R}^{2}=0.5458$ \\
ssp6 & $\mathrm{y}=0.0358 \mathrm{x}+14.639$ & $\mathrm{R}^{2}=0.5306$ \\
ssp6 & $\mathrm{y}=0.0286 \mathrm{x}+13.015$ & $\mathrm{R}^{2}=0.4887$ \\
\hline
\end{tabular}

Table 4: MK trend analysis of minimum temperature in Jimma Zone (1980-2020).

\begin{tabular}{lllllll}
\hline Senario & Z-value & Sen's slope & S & Var(s) & P-value & Tau \\
\hline SSP2.6 & $4.998212 \mathrm{e}+00$ & $2.711876 \mathrm{e}-02$ & $4.460000 \mathrm{e}+02$ & $7.926667 \mathrm{e}+03$ & $5.786421 \mathrm{e}-07$ & $5.439024 \mathrm{e}-01$ \\
\hline Ssp 4.5 & $5.290243 \mathrm{e}+00$ & $4.484448 \mathrm{e}-02$ & $4.720000 \mathrm{e}+02$ & $7.926667 \mathrm{e}+03$ & $1.221541 \mathrm{e}-07$ & $5.756098 \mathrm{e}-01$ \\
SSP6 & $5.088068 \mathrm{e}+00$ & $3.513125 \mathrm{e}-02$ & $4.540000 \mathrm{e}+02$ & $7.926667 \mathrm{e}+03$ & $3.617297 \mathrm{e}-07$ & $5.536585 \mathrm{e}-01$ \\
SSP8.5 & $5.020676 \mathrm{e}+00$ & $2.496125 \mathrm{e}-02$ & $4.480000 \mathrm{e}+02$ & $7.926667 \mathrm{e}+035$ & $5.148986 \mathrm{e}-07$ & $5.463415 \mathrm{e}-01$ \\
\hline
\end{tabular}




\section{Tmax}

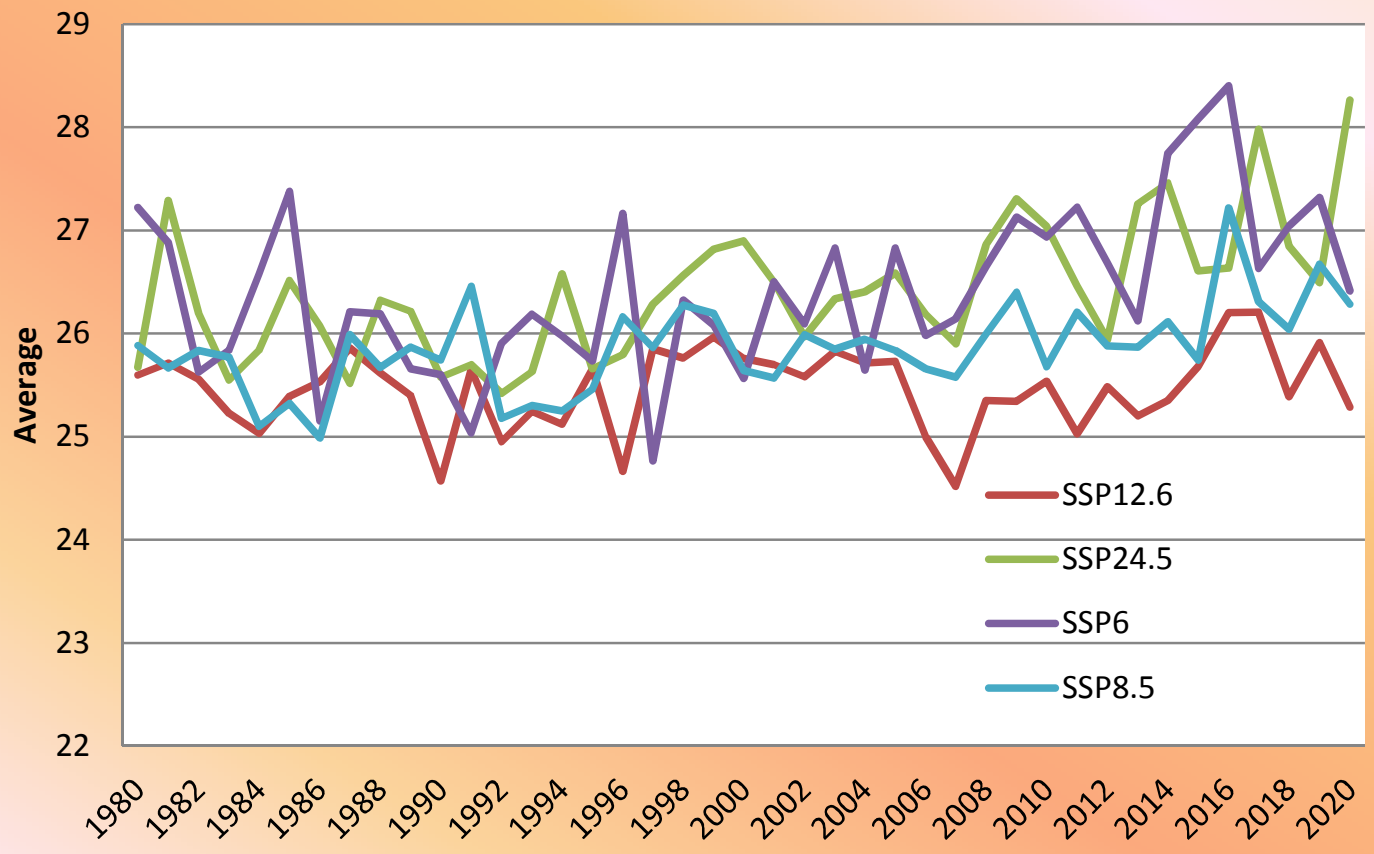

Figure 4 : Trend analysis of maximum temperature for Jimma zone from 1980-2020

Table 5: Slope of maximum temperature for jimma zone from 1980-2020

\begin{tabular}{llc}
\hline Trend & slope & \\
\hline ssp12.6 & $\mathrm{y}=0.0044 \mathrm{x}+25.375$ & $\mathrm{R}^{2}=0.0181$ \\
ssp4.5 & $\mathrm{y}=0.0331 \mathrm{x}+25.723$ & $\mathrm{R}^{2}=0.3536$ \\
ssp6 & $\mathrm{y}=0.0301 \mathrm{x}+25.796$ & $\mathrm{R}^{2}=0.2041$ \\
ssp6 & $\mathrm{y}=0.0192 \mathrm{x}+25.462$ & $\mathrm{R}^{2}=0.2808$ \\
\hline
\end{tabular}

Table 6: MK trend analysis of maximum temperature in Jimma Zone (1980-2020

\begin{tabular}{lllllll}
\hline Senario & Z-value & Sen's slope & S & Var(s) & P-value & Tau \\
\hline SSP2.6 & $5.728288 \mathrm{e}-01$ & $4.003201 \mathrm{e}-03$ & $5.200000 \mathrm{e}+01$ & $7.926667 \mathrm{e}+03$ & $5.667606 \mathrm{e}-01$ & $6.341463 \mathrm{e}-02$ \\
Ssp 4.5 & $4.032266 \mathrm{e}+00$ & $3.312415 \mathrm{e}-02$ & $3.600000 \mathrm{e}+02$ & $7.926667 \mathrm{e}+03$ & $5.524166 \mathrm{e}-05$ & $4.390244 \mathrm{e}-01$ \\
SSP6 & $2.864144 \mathrm{e}+00$ & $3.250476 \mathrm{e}-02$ & $2.560000 \mathrm{e}+02$ & $7.926667 \mathrm{e}+03$ & $4.181376 \mathrm{e}-03$ & $3.121951 \mathrm{e}-01$ \\
SSP8.5 & $3.246030 \mathrm{e}+00$ & $1.781687 \mathrm{e}-02$ & $2.900000 \mathrm{e}+02$ & $7.926667 \mathrm{e}+03$ & $1.170265 \mathrm{e}-03$ & $3.536585 \mathrm{e}-0$ \\
\hline
\end{tabular}

\section{Conclusion}

Ethiopia is vulnerable to climate variability, and climate change is likely to increase the frequency and magnitude of disasters. Adverse impacts of climate change may worsen existing social and economic challenges of the whole country, particularly where people are dependent on resources that are sensitive to climate change and rain-fed agriculture. This study was undertaken to analyze rainfall and Temperature trend in Jimma zone, ONRS of Ethiopia. The study employed Mann-Kendall's test to detect change in rainfall trends. Results for rainfall trend analysis for Jimma zone indicated decreasing trends; overall, the observed trends were not statistically significant at $1 \%$ and $5 \%$. The major problem as far as rainfall distribution is concerned in the study area is more of the inconsistency as well as a change in onset and cessation periods than the total amount. The rain onsets late and ends up very early-which makes the cropping calendar being shorter than before. Moreover, erratic rainfalls as well as prolonged dry-spell periods during the main rain season have reported as major phenomena which adversely affect agricultural activity. The mean temperature in the study area ranges from $20^{\prime} \mathrm{C}$ to 25 ' $\mathrm{C}$ with annual average temperature of $22^{\circ} \mathrm{C}$. The rate of change of temperature was found to be $0.0181,0.3536,0.2041$ and 0.026 ' $\mathrm{C}$ per decade for mean, minimum and maximum respectively during the period of 1980-2020.

The Mann-kendall trend analysis test result revealed that he trend for maximum temperature exhibited nonsignificant increasing trend while a significant increasing trend for minimum temperature was obtained for all months (the rate for the minimum is more pronounced than the maximum). The overall increase in annual temperature observed in the study area is, therefore, largely attributed to an increase in the minimum temperature. 
It is, therefore, imperative to adjust the agriculture activity with the variability situation and design planned climate change adaptation strategies so as to enhance the adaptive capacity and resilience of rainfed dependent smallholder farmers

\section{Reference}

Alhamshry, A., Fenta, A. A., Yasuda, H., Kimura, R., \& Shimizu, K. (2020). Seasonal rainfall variability in Ethiopia and its long-term link to global sea surface temperatures. Water (Switzerland), 12(1), 1-19. https://doi.org/10.3390/w12010055

Almazroui, M., Islam, M. N., Saeed, F., Saeed, S., Ismail, M., Ehsan, M. A., Diallo, I., O’Brien, E., Ashfaq, M., Martínez-Castro, D., Cavazos, T., Cerezo-Mota, R., Tippett, M. K., Gutowski, W. J., Alfaro, E. J., Hidalgo, H. G., Vichot-Llano, A., Campbell, J. D., Kamil, S., ... Barlow, M. (2021). Projected Changes in Temperature and Precipitation Over the United States, Central America, and the Caribbean in CMIP6 GCMs. Earth Systems and Environment, 5(1), 1-24. https://doi.org/10.1007/s41748-021-00199-5

Almazroui, M., Saeed, F., Saeed, S., Nazrul Islam, M., Ismail, M., Klutse, N. A. B., \& Siddiqui, M. H. (2020a). Projected Change in Temperature and Precipitation Over Africa from CMIP6. Earth Systems and Environment, 4(3), 455-475. https://doi.org/10.1007/s41748-020-00161-x

Almazroui, M., Saeed, F., Saeed, S., Nazrul Islam, M., Ismail, M., Klutse, N. A. B., \& Siddiqui, M. H. (2020b). Projected Change in Temperature and Precipitation Over Africa from CMIP6. Earth Systems and Environment, 4(3), 455-475. https://doi.org/10.1007/s41748-020-00161-x

B. Barana, B. (2017). Spatial and Temporal Rainfall Trend Analysis : A Case Study of. Civil and Environmental Research, 9(8), 1-9.

Birara, H., \& Mishra, R. P. P. S. K. (2020). Projections of future rainfall and temperature using statistical downscaling techniques in Tana Basin, Ethiopia. Sustainable Water Resources Management, 1. https://doi.org/10.1007/s40899-020-00436-1

Fazzini, M., Bisci, C., \& Billi, P. (2015). The Climate of Ethiopia. World Geomorphological Landscapes, October, 65-87. https://doi.org/10.1007/978-94-017-8026-1

Feyissa, G., Zeleke, G., Bewket, W., \& Gebremariam, E. (2018). Downscaling of future temperature and precipitation extremes in Addis Ababa under climate change. Climate, 6(3). https://doi.org/10.3390/cli6030058

Gebrechorkos, S. H., Hülsmann, S., \& Bernhofer, C. (2019). Changes in temperature and precipitation extremes in Ethiopia, Kenya, and Tanzania. International Journal of Climatology, 39(1), 18-30. https://doi.org/10.1002/joc.5777

Gidden, M. J., Riahi, K., Smith, S. J., Fujimori, S., Luderer, G., Kriegler, E., Van Vuuren, D. P., Van Den Berg, M., Feng, L., Klein, D., Calvin, K., Doelman, J. C., Frank, S., Fricko, O., Harmsen, M., Hasegawa, T., Havlik, P., Hilaire, J., Hoesly, R., ... Takahashi, K. (2019). Global emissions pathways under different socioeconomic scenarios for use in CMIP6: A dataset of harmonized emissions trajectories through the end of the century. Geoscientific Model Development, 12(4), 1443-1475. https://doi.org/10.5194/gmd-12-1443-2019

Girma, E., Tino, J., \& Wayessa, G. (2016). Rainfall trend and variability analysis in Setema-Gatira area of Jimma, Southwestern Ethiopia. African Journal of Agricultural Research, 11(32), 3037-3045. https://doi.org/10.5897/ajar2015.10160

Klutse, N. A. B., Quagraine, K. A., Nkrumah, F., Quagraine, K. T., Berkoh-Oforiwaa, R., Dzrobi, J. F., \& Sylla, M. B. (2021). The Climatic Analysis of Summer Monsoon Extreme Precipitation Events over West Africa in CMIP6 Simulations. Earth Systems and Environment, 5(1), 25-41. https://doi.org/10.1007/s41748-02100203-y

Miheretu, B. A. (2020). Temporal variability and trend analysis of temperature and rainfall in the Northern highlands of Ethiopia. Physical Geography, 00(00), 1-18. https://doi.org/10.1080/02723646.2020.1806674

Molla, M. A., \& Fitsume, Y. D. (2017). Seasonal rainfall and crop productivity in South West Ethiopia: Preliminary analysis for recent climate. International Journal of Water Resources and Environmental Engineering, 9(10), 211-217. https://doi.org/10.5897/ijwree2017.0730

Yang, X., Zhou, B., Xu, Y., \& Han, Z. (2021). CMIP6 Evaluation and Projection of Temperature and Precipitation over China. Advances in Atmospheric Sciences, 38(5), 817-830. https://doi.org/10.1007/s00376-021-0351-4 